\title{
Timing of balloon atrial septostomy in patients with d-TGA and association with birth location and patient outcomes
}

Courtney Thomas ( $\nabla$ coutho@med.umich.edu )

Michigan Congenital Heart Center, CS Mott Children's Hospital Ann Arbor

\section{Sunkyung Yu}

Michigan Congenital Heart Center, CS Mott Children's Hospital Ann Arbor

Ray Lowery

Michigan Congenital Heart Center, CS Mott Children's Hospital Ann Arbor

Jeffrey D. Zampi

Michigan Congenital Heart Center, CS Mott Children's Hospital Ann Arbor

\section{Research Article}

Keywords: transposition of the great arteries, balloon atrial septostomy, patient outcomes, prenatal diagnosis

Posted Date: February 25th, 2022

DOI: https://doi.org/10.21203/rs.3.rs-1389473/v1

License: (9) This work is licensed under a Creative Commons Attribution 4.0 International License. Read Full License 


\section{Abstract}

Patients with d-looped transposition of the great arteries (d-TGA), especially those without an adequate atrial septal defect, can experience severe hypoxemia and hemodynamic compromise in the neonatal period. This can be mitigated by urgent balloon atrial septostomy (BAS). However, some patients with dTGA are born at centers without this capability. The aim of this retrospective study of d-TGA patients who had urgent or emergent BAS at our institution between 2010 and 2021 was to evaluate time from birth to BAS for infants born at a tertiary care center as compared to those requiring transport from other institutions and to examine correlation between time to BAS and patient outcomes. Our primary outcome was time from birth to BAS. Secondary outcomes included hospital and ICU length of stay, mortality, and evidence of pulmonary or neurologic abnormalities including pulmonary hypertension, abnormal neuroimaging, or seizures. Of 96 patients, 67 (70\%) were born at our institution. The median time to BAS was 4 hours for patients born at our institution vs. 14.1 hours for those born elsewhere $(p<.0001)$. A longer time from birth to BAS was associated with longer ICU $(r=0.21, p=0.046)$ and hospital length of stay $(r=0.24, p=0.02)$ and increased likelihood of elevated right ventricular pressure on post-operative discharge echocardiogram $(p=0.01)$. There were no differences in mortality between the groups. Therefore, prenatal planning for patients with known d-TGA should include a delivery plan with access to urgent BAS.

\section{Introduction}

Transposition of the great arteries is the most common form of cyanotic congenital heart disease with dlooped transposition (d-TGA) accounting for $5-7 \%$ of all congenital heart defects [1]. In the initial postnatal period, patients with d-TGA may be subject to profound hypoxemia and resulting hemodynamic compromise if intracardiac mixing of blood is inadequate. Given the high-risk postnatal period, studies have shown that expedited access to medical and interventional therapies have improved outcomes and survival for neonates with d-TGA [2]. While pre-operative management and surgical timing vary by institution, pulse oximetry monitoring, transthoracic echocardiography, and initiation of prostaglandin E1 (PGE) are generally recognized as important components of initial management. Additionally, for infants with prohibitive hypoxemia and a restrictive atrial septum, balloon atrial septostomy (BAS) is a wellestablished method of improving intracardiac mixing and hemodynamic status [3]. However, not all infants with d-TGA and inadequate atrial mixing are born at centers with the ability to rapidly perform BAS procedures. Prior studies have attempted to look at outcomes related to birth location, but these data have been conflicted and often limited to broad outcomes like mortality.

This study aimed to evaluate our center's experience with timing of BAS in infants with d-TGA comparing infants born at our center and those requiring transport from other institutions and how this timing and birth location relates to overall outcomes. In addition, besides mortality, we examined other outcomes including hospital and intensive care unit (ICU) length of stay, as well as markers of pulmonary and neurologic sequelae of prolonged hypoxemia. 


\section{Methods}

Study Design

After obtaining Institutional Review Board approval, we performed a single center retrospective study of all neonates with d-TGA or d-TGA physiology who underwent urgent or emergent BAS at our institution between 2010 and 2021. An urgent BAS was defined as a BAS occurring within the first 48 hours of life (or upon arrival to our center if more than 48 hours of life) with evidence of poor oxygenation (SpO2< $70 \%$ on room air, $\mathrm{FiO} 2$ requirement $>40 \%$ with or without mechanical ventilation) but without hemodynamic instability. An emergent BAS was defined as a BAS occurring within the first 48 hours of life (or upon arrival to our center) with evidence of significantly compromised oxygenation ( $\mathrm{PaO} 2<$ $30 \mathrm{mmHg}$ or $\mathrm{SpO} 2<70 \%$ on room air with mechanical ventilation and an $\mathrm{FiO} 2$ requirement $>60 \%$ ) and/or hemodynamic instability ( $\mathrm{pH}<7.3$ or requiring ionotropic support). Patients were excluded from the study if they underwent an elective BAS at more than 48 hours of life, did not undergo a BAS, or had a BAS at an outside institution prior to transfer to our center. All patients had their diagnosis confirmed via postnatal echocardiography. Patients were identified using our internal cardiac catheterization database and the institutional Electronic Medical Record Search Engine (EMERSE)[4].

\section{Variables}

In addition to patient demographics, gestational age and birth characteristics, prenatal factors were collected including location of prenatal care and for those patients with a prenatal diagnosis, location of fetal echocardiogram, fetal diagnosis and atrial septal characteristics, and location of fetal cardiology consultation. Postnatal but pre-BAS variables included need for intubation, ionotropic support, or cardiopulmonary resuscitation (CPR) as well as highest FiO2, lowest and highest oxygen saturation on pulse oximetry, and laboratory values including $\mathrm{pH}, \mathrm{PaO} 2$, and lactate. Details of the postnatal echocardiogram were also collected including the specific d-TGA physiology, atrial septal characteristics, presence of a patent ductus arteriosus (PDA), and ventricular function. BAS procedural characteristics were collected including the time from birth to ASD creation and procedural complications. Duration of mechanical ventilation, ICU and hospital length of stay, need for extracorporeal membrane oxygenation (ECMO), and survival were collected for both the time period between BAS and definitive surgical repair and time period after definitive surgical repair. We also collected the need for inhaled nitric oxide (iNO) during these time periods as well as right ventricular (RV) pressure on discharge echocardiogram. Markers of neurologic injury as indicated by clinical or subclinical seizures or abnormal neuroimaging were also collected. Lastly, long-term outcomes including vital status at most recent follow-up were collected for all patients.

\section{Outcomes}

The primary outcome of the study was time from birth to BAS. Secondary outcomes included mortality, hospital and ICU length of stay, duration of mechanical ventilation, evidence of pulmonary hypertension (as defined by pulmonary vasodilator requirement, either inhaled nitric oxide or oral therapy, or elevated 
RV pressures on post-operative discharge echocardiogram), and neurologic abnormalities including abnormal neuroimaging or seizures.

\section{Statistical Analysis}

Data are described as frequencies with percentage (\%) for categorical variables and median with interquartile range (IQR) or mean \pm standard deviation for continuous variables. Patient demographics, birth and clinical characteristics, and outcomes were compared between infants born at our center and those delivered elsewhere using Chi-square test or Fisher's exact test for categorical variables and Wilcoxon rank sum test or two-sample t-test for continuous variables. Univariate associations of time from birth to BAS with birth location and patient outcomes were examined using Wilcoxon rank sum test for categorical variables and Spearman correlation coefficient, $r$, for continuous variables. All analyses were performed using SAS Version 9.4 (SAS Institute Inc., Cary, NC), with statistical significance set at a p-value $<0.05$ using a two-sided test.

\section{Results}

Of 217 patients with d-TGA or d-TGA physiology who underwent neonatal surgical intervention at our institution during the study period, a total of $96(44 \%)$ patients required an emergent or urgent BAS and were included in the analysis. The patient demographics are shown in Table 1 . The majority of patients were prenatally diagnosed with d-TGA and of the prenatally diagnosed infants, $97 \%$ received a prenatal consultation at our congenital heart center. Only two of the patients who had prenatal consultation at our institution ( $\mathrm{U}$ of $\mathrm{M})$ delivered outside our institution, both due to maternal presentation for urgent induction of labor. The infants born at other hospitals had a median travel distance of 99 miles (IQR 56115 ) and the transport time was a median of 10.3 hours (IQR 6.8-12.0). When comparing the infants born outside our institution with and without a prenatal diagnosis, the transport time was a median of 6.4 hours (IQR 4.0-6.8) vs. 10.7 hours (IQR 7.9-13.5), respectively. 
Table 1

Patient demographics and prenatal and birth characteristics ( $\mathrm{N}=96)$

\section{Birth Location}

\begin{tabular}{|c|c|c|c|c|}
\hline & $\begin{array}{l}\text { All } \\
(\mathrm{N}=96)\end{array}$ & $\begin{array}{l}U \text { of } M \\
(N=67)\end{array}$ & $\begin{array}{l}\text { Other } \\
(N=29)\end{array}$ & $\begin{array}{l}\text { P- } \\
\text { value§ }\end{array}$ \\
\hline Male sex & $70(72.9)$ & $49(73.1)$ & $21(72.4)$ & 0.94 \\
\hline Caucasian race & $80(83.3)$ & $55(82.1)$ & $25(86.2)$ & 0.77 \\
\hline Known genetic disorder & $4(4.2)$ & $3(4.5)$ & $1(3.4)$ & 1.00 \\
\hline Non-cardiac anomalies & $14(14.6)$ & $10(14.9)$ & $4(13.8)$ & 1.00 \\
\hline Prenatal diagnosis & $69(71.9)$ & $66(98.5)$ & $3(10.3)$ & $<.0001$ \\
\hline Type of prenatal diagnosis & & & & $0.15^{\ddagger}$ \\
\hline dTGA/VSD & $\begin{array}{l}17 / 69 \\
(24.6)\end{array}$ & $\begin{array}{l}15 / 66 \\
(22.7)\end{array}$ & $\begin{array}{l}2 / 3 \\
(66.7)\end{array}$ & \\
\hline dTGA/IVS & $\begin{array}{l}47 / 69 \\
(68.1)\end{array}$ & $\begin{array}{l}46 / 66 \\
(69.7)\end{array}$ & $\begin{array}{l}1 / 3 \\
(33.3)\end{array}$ & \\
\hline dTGA/Other & $5 / 69(7.2)$ & $5 / 66(7.6)$ & $0 / 3(0.0)$ & \\
\hline Other non-cardiac anomalies seen & $5 / 69(7.2)$ & $5 / 66(7.6)$ & $0 / 3(0.0)$ & 1.00 \\
\hline Initial fetal echocardiogram at $\mathrm{U}$ of $\mathrm{M}$ & $\begin{array}{l}39 / 69 \\
(56.5)\end{array}$ & $\begin{array}{l}38 / 66 \\
(57.6)\end{array}$ & $\begin{array}{l}1 / 3 \\
(33.3)\end{array}$ & 0.58 \\
\hline $\mathrm{U}$ of $\mathrm{M}$ fetal cardiology consultation & $\begin{array}{l}67 / 69 \\
(97.1)\end{array}$ & $\begin{array}{l}65 / 66 \\
(98.5)\end{array}$ & $\begin{array}{l}2 / 3 \\
(66.7)\end{array}$ & 0.09 \\
\hline Location of prenatal care & & & & 0.27 \\
\hline U of M & $10(10.4)$ & $9(13.4)$ & $1(3.4)$ & \\
\hline Other & $86(89.6)$ & $58(86.6)$ & $28(96.6)$ & \\
\hline Manner of delivery & & & & 0.75 \\
\hline SVD & $64(66.7)$ & $44(65.7)$ & $20(69.0)$ & \\
\hline C-section & $32(33.3)$ & $23(34.3)$ & $9(31.0)$ & \\
\hline $\begin{array}{l}\text { Change in delivery plan due to concern for fetal } \\
\text { depression }\end{array}$ & $6(6.3)$ & $4(6.0)$ & $2(6.9)$ & 1.00 \\
\hline Birth weight, kg & $3.4 \pm 0.5$ & $3.4 \pm 0.5$ & $3.3 \pm 0.4$ & 0.41 \\
\hline Gestational age, weeks & $\begin{array}{l}39(38- \\
39)\end{array}$ & $\begin{array}{l}39(38- \\
39)\end{array}$ & $\begin{array}{l}39(38- \\
40)\end{array}$ & \\
\hline
\end{tabular}




\begin{tabular}{|llll|}
\hline \multicolumn{3}{|c|}{ Birth Location } \\
\hline Preterm (gestational age < 37 weeks) & $8(8.3)$ & $6(9.0)$ & $2(6.9)$
\end{tabular}

The clinical characteristics prior to BAS are described in Table 2. Infants delivered outside our institution had lower minimum PaO2 $(p=0.02)$ and were more likely to require ionotropic support $(p<.0001)$. The median APGAR score at both 1 minute and 5 minutes was 8 and there was no difference in the APGAR scores of infants born at $\mathrm{U}$ of $\mathrm{M}$ compared to those delivered elsewhere. There were no significant differences in the postnatal echocardiogram findings between the groups. 
Table 2

Clinical and echocardiogram characteristics prior to septostomy by birth location $(\mathrm{N}=96)$

\section{Birth Location}

\begin{tabular}{|c|c|c|c|c|}
\hline Characteristics & $\begin{array}{l}\text { All } \\
(\mathrm{N}=96)\end{array}$ & $\begin{array}{l}\text { U of } M \\
(N=67)\end{array}$ & $\begin{array}{l}\text { Other } \\
(\mathrm{N}=29)\end{array}$ & $\begin{array}{l}\text { P- } \\
\text { value§ }\end{array}$ \\
\hline Intubation at birth & $64(66.7)$ & $42(62.7)$ & $22(75.9)$ & 0.21 \\
\hline CPR needed at birth & $3(3.1)$ & $2(3.0)$ & $1(3.4)$ & 1.00 \\
\hline FiO2 required prior to septostomy & $91(94.8)$ & $62(92.5)$ & $29(100.0)$ & 0.32 \\
\hline Highest FiO2 $=100 \%$ & $82 / 91(90.1)$ & $54 / 62(87.1)$ & $\begin{array}{l}28 / 29 \\
(96.6)\end{array}$ & 0.26 \\
\hline iNO administered prior to septostomy & $5(5.2)$ & $5(7.5)$ & $0(0.0)$ & 0.32 \\
\hline \multicolumn{5}{|l|}{$\mathrm{O}_{2}$ saturation } \\
\hline Highest, \% & $80.0 \pm 10.2$ & $79.1 \pm 10.2$ & $82.0 \pm 10.1$ & 0.21 \\
\hline Lowest, \% & $53.3 \pm 18.8$ & $51.4 \pm 19.2$ & $57.8 \pm 17.4$ & 0.13 \\
\hline Inotropic support & $19(19.8)$ & $5(7.5)$ & $14(48.3)$ & $<.0001$ \\
\hline PGE & $93(96.9)$ & $64(95.5)$ & $29(100.0)$ & 0.55 \\
\hline Lowest $\mathrm{pH}<7.3$ & $37 / 69(53.6)$ & $24 / 44(54.5)$ & $\begin{array}{l}13 / 25 \\
(52.0)\end{array}$ & 0.84 \\
\hline If initial $\mathrm{pH}<7.3$, time to $\mathrm{pH} \geq 7.3$, hours & $6.8(3.5-10.2)$ & $6.6(3.7-10.5)$ & $\begin{array}{l}7.6(2.9- \\
8.8)\end{array}$ & 0.95 \\
\hline Lowest $\mathrm{PaO}_{2}, \mathrm{mmHg}$ & $\begin{array}{l}30.3(27.3- \\
35.2)\end{array}$ & $\begin{array}{l}31.9(28.4- \\
36.6)\end{array}$ & $\begin{array}{l}28.2(26- \\
31)\end{array}$ & 0.02 \\
\hline Lowest $\mathrm{PaO}_{2}<30 \mathrm{mmHg}$ & $32 / 69(46.4)$ & $19 / 44(43.2)$ & $\begin{array}{l}13 / 25 \\
(52.0)\end{array}$ & 0.48 \\
\hline Highest Lactate, $\mathrm{mmol} / \mathrm{L}(\mathrm{N}=58)$ & $3.6(2.6-5.4)$ & $3.7(2.6-5.4)$ & $\begin{array}{l}3.2(2.8- \\
5.9)\end{array}$ & 0.84 \\
\hline
\end{tabular}

\section{Echocardiogram Findings prior to Septostomy}

Postnatal diagnosis

$0.11^{\ddagger}$

$\begin{array}{llll}\text { dTGA/VSD } & 23(24.0) & 13(19.4) & 10(34.5) \\ \text { dTGA/IVS } & 68(70.8) & 49(73.1) & 19(65.5) \\ \text { dTGA/DORV } & 5(5.2) & 5(7.5) & 0(0.0)\end{array}$

Atrial septal characteristics 


\begin{tabular}{|c|c|c|c|c|}
\hline \multicolumn{5}{|c|}{ Birth Location } \\
\hline Intact & $1(1.0)$ & $1(1.5)$ & \multicolumn{2}{|l|}{$0(0.0)$} \\
\hline PFO & $95(99.0)$ & $66(98.5)$ & \multicolumn{2}{|l|}{$29(100.0)$} \\
\hline PDA present & $96(100.0)$ & $67(100.0)$ & $29(100.0)$ & $\mathrm{N} / \mathrm{A}$ \\
\hline Large & $72(75.0)$ & $49(73.1)$ & $23(79.3)$ & \\
\hline \multicolumn{4}{|l|}{ Ventricular function } & \multirow[t]{2}{*}{$1.00^{\mathrm{a}}$} \\
\hline Normal/Low-normal & $91(94.8)$ & $63(94.0)$ & $28(96.6)$ & \\
\hline Mildly depressed & $1(1.0)$ & $0(0.0)$ & \multicolumn{2}{|l|}{$1(3.4)$} \\
\hline Mild-Moderately depressed & $3(3.1)$ & $3(4.5)$ & \multicolumn{2}{|l|}{$0(0.0)$} \\
\hline Moderately depressed & $0(0.0)$ & $0(0.0)$ & \multicolumn{2}{|l|}{$0(0.0)$} \\
\hline Severely depressed & $1(1.0)$ & $1(1.5)$ & \multicolumn{2}{|l|}{$0(0.0)$} \\
\hline Aortic arch obstruction & $7(7.3)$ & $6(9.0)$ & $1(3.4)$ & 0.67 \\
\hline \multicolumn{5}{|c|}{$\begin{array}{l}\text { * Data are presented as } \mathrm{N}(\%) \text { for categorical variables and Median (interquartile range) or Mean } \pm \\
\text { Standard deviation for continuous variables. }\end{array}$} \\
\hline \multicolumn{5}{|c|}{$\begin{array}{l}\S \text { P-value from Chi-square test or Fisher's exact test for categorical variables and Wilcoxon rank sum } \\
\text { test or two-sample t-test for continuous variables. }\end{array}$} \\
\hline \multicolumn{5}{|c|}{$\begin{array}{l}\text { ₹ Type of postnatal diagnosis was compared as dTGA/VSD vs. all others and p-value came from Chi- } \\
\text { square test. }\end{array}$} \\
\hline
\end{tabular}

Figure 1 demonstrates the time from birth to BAS for the two groups. Infants who were delivered outside our institution had the median time from birth to BAS that is nearly 10 hours longer than those born at $\mathrm{U}$ of $\mathrm{M}$. The median time of arrival in the lab was 14 hours in patients born elsewhere vs. 3.4 hours in patients born at $\mathrm{U}$ of $\mathrm{M}$ but the time from procedure start to septostomy and total procedure duration are comparable between the two groups, as shown in Table 3. Overall, the median time from procedure start to septostomy was 16 minutes and the median total procedure duration was 52 minutes. Additionally, the number of procedures performed during typical daytime operations versus after hours was similar between groups. Septostomy procedural complications were rare, occurring in 5 patients (5\%). While it was not significantly different between the groups, the two patients who had cardiac arrests during their septostomy procedures were both delivered outside our institution. The other major complication was a pericardial effusion requiring treatment $(n=1)$. Minor complications included transient 2:1 heart block, transient supraventricular tachycardia (SVT), and prolonged bleeding from the femoral venous access site $(n=1$ each). 
Table 3

Septostomy characteristics by birth location $(\mathrm{N}=96)$

\section{Birth Location}

\begin{tabular}{|c|c|c|c|c|}
\hline Characteristics & $\begin{array}{l}\text { All } \\
(\mathrm{N}=96)\end{array}$ & $\begin{array}{l}U \text { of } M \\
(N=67)\end{array}$ & $\begin{array}{l}\text { Other } \\
(\mathrm{N}=29)\end{array}$ & $\begin{array}{l}\text { P- } \\
\text { value }\end{array}$ \\
\hline "After hours" procedure & $33(34.4)$ & $22(32.8)$ & $11(37.9)$ & 0.63 \\
\hline Time from birth to procedure start, hours & $\begin{array}{l}4.9(2.3- \\
12.8)\end{array}$ & $\begin{array}{l}3.4(1.9- \\
6.7)\end{array}$ & $\begin{array}{l}14.0(8.7- \\
24.2)\end{array}$ & $<.0001$ \\
\hline After hours & $\begin{array}{l}4.6(3.1- \\
12.4)\end{array}$ & $\begin{array}{l}3.4(2.2- \\
4.6)\end{array}$ & $\begin{array}{l}13.2(8.0- \\
30.0)\end{array}$ & 0.001 \\
\hline Daytime hours & $\begin{array}{l}5.1(2.1- \\
13.4)\end{array}$ & $\begin{array}{l}3.4(1.8- \\
7.0)\end{array}$ & $16.9(9-24.2)$ & $<.0001$ \\
\hline $\begin{array}{l}\text { Time from procedure start to septostomy, } \\
\text { minutes }\end{array}$ & $16(9-26)$ & $17(9-26)$ & $14(9-26)$ & 0.66 \\
\hline After hours & $24(12-37)$ & $24(13-37)$ & $23(8-42)$ & 0.52 \\
\hline Daytime hours & $15(9-22)$ & $16(9-21)$ & $13.5(9-22)$ & 0.90 \\
\hline Procedure duration, minutes & $52(37-71.5)$ & $51(37-79)$ & $52(37-71)$ & 0.92 \\
\hline After hours & $59(39-74)$ & $\begin{array}{l}59.5(46- \\
80)\end{array}$ & $52(33-71)$ & 0.48 \\
\hline Daytime hours & $50(35-69)$ & $49(35-64)$ & $58.5(40-69)$ & 0.53 \\
\hline Urgency of septostomy & & & & 0.98 \\
\hline Emergent & $73(76.0)$ & $51(76.1)$ & $22(75.9)$ & \\
\hline Urgent & $23(24.0)$ & $16(23.9)$ & $7(24.1)$ & \\
\hline Cardiac arrest during septostomy & $2(2.1)$ & $0(0.0)$ & $2(6.9)$ & 0.09 \\
\hline \multicolumn{5}{|c|}{$\begin{array}{l}\text { * Data are presented as } \mathrm{N}(\%) \text { for categorical variables and Median (interquartile range) for } \\
\text { continuous variables. }\end{array}$} \\
\hline
\end{tabular}

Outcomes of interest were evaluated both after septostomy/prior to surgery as well as after surgery and prior to discharge. There were no significant differences in the post-septostomy/pre-surgery hospital courses based on time to septostomy (Table 4) or location of birth. Of note, the median age at time of surgery and median time between septostomy and surgery were the similar between groups ( 5 and 4 days for patients born at $U$ of $M, 5$ and 5 days for patients born elsewhere, $p=0.27$ and $p=0.89$, respectively). 
Table 4

Associations of time from birth to septostomy with patient outcomes: post-septostomy/ prior to surgery

\section{Patient outcomes}

FiO2 required

Yes

No

iNO required

PGE continued

Mechanica

ventilation

Yes

No

Yes

No

Yes

\section{N}

68

Duration of iNO

Initial duration of

intubation, days

Reintubation

No reintubation

Total duration of intubation, days

No

Yes

No

Brain imaging

Yes

Normal findings

Abnormal findings

No

Yes

No

Cardiac arrest

Yes

28

17

2

94

Time from birth to septostomy, hours

Pvalue

0.74

$5.5(2.9-13.5)$

$5.8(2.2-11.3)$

$3.8(2.5-5.9)$

0.22

$r=0.30$

0.25

79

$6.4(3.1-13.6)$

73

$5.4(2.6-13.1)$

0.61

20

$5.4(4.1-115.2)$

86

$5.2(2.5-13.4)$

0.31

$r=0.07$

0.55

$13 / 86$

$4.0(2.4-6.1)$

0.14

$73 / 86 \quad 5.6(2.8-15.5)$

$r=0.0001$ 1.00

10

$7.5(5.1-13.1)$

4

$3.2(2.2-4.7)$

0.15

92

$5.9(2.7-13.5)$

54

$5.3(2.8-12.8)$

0.96

37/54 $7.7(3.7-15.5)$

0.03

$17 / 54 \quad 4.0(2.5-5.4)$

42

$6.6(2.5-13.6)$

16.1 (10.2-22.0)

0.18

$5.3(2.6-13.1)$

* Data are presented as Median with interquartile range or $r$, Spearman correlation coefficient, as appropriate.

$\S$ P-value from Wilcoxon rank sum test for categorical variables and Spearman correlation coefficient for continuous variables. 
After definitive cardiac surgery, a longer time from birth to BAS was associated with a longer ICU length of stay $(r=0.21, p=0.046)$ as well as a longer total hospital length of stay $(r=0.24, p=0.02)$ (Table 5).

There was no difference in the use of inhaled or oral pulmonary vasodilators, however infants with a longer time from birth to BAS were more likely to have elevated RV pressure on discharge echocardiogram $(p=0.01)$. There were no differences in frequency of seizures or abnormal neuroimaging based on time to BAS or birth location. During median 3.8 years of follow-up (IQR 1.3-6.8), there were 6 $(6 \%)$ deaths and the majority of them occurred within the first year of life, with 5 of the 6 deaths occurring within 6 months of BAS. There was no significant difference in mortality with longer time to BAS or between the group of patients born at $\mathrm{U}$ of $\mathrm{M}$ and those delivered outside our institution. 
Table 5

Associations of time from birth to septostomy with patient outcomes: post-surgery and overall

\begin{tabular}{|c|c|c|c|c|}
\hline \multicolumn{2}{|l|}{ Patient outcomes } & \multirow{2}{*}{$\begin{array}{l}\mathbf{N} \\
28\end{array}$} & \multirow{2}{*}{$\begin{array}{l}\text { Time from birth to } \\
\text { septostomy, hours } \\
5.8(3.6-11.3)\end{array}$} & \multirow{2}{*}{$\begin{array}{l}\begin{array}{l}\text { P- } \\
\text { value }\end{array} \\
0.68\end{array}$} \\
\hline Delayed sternal closure & Yes & & & \\
\hline & No & 64 & $5.1(2.5-13.9)$ & \\
\hline \multirow[t]{2}{*}{ ECMO post-surgery } & Yes & 6 & $4.9(3.1-12.8)$ & 0.97 \\
\hline & No & 86 & $5.7(2.6-13.4)$ & \\
\hline \multirow[t]{2}{*}{ iNO required post-surgery } & Yes & 8 & $11.1(4.9-27.8)$ & 0.18 \\
\hline & No & 84 & $5.2(2.6-12.7)$ & \\
\hline $\begin{array}{l}\text { Total iNO duration during } \\
\text { hospitalization }\end{array}$ & & 21 & $r=0.29$ & 0.21 \\
\hline \multirow[t]{2}{*}{ Sildenafil required } & Yes & 5 & $7.3(5.0-10.2)$ & 0.61 \\
\hline & No & 91 & $5.4(2.6-13.4)$ & \\
\hline \multirow[t]{2}{*}{$\begin{array}{l}\text { RV pressure on discharge } \\
\text { echocardiogram }\end{array}$} & $\begin{array}{l}\text { More than half } \\
\text { systemic }\end{array}$ & 18 & $11.3(5.6-24.3)$ & 0.01 \\
\hline & $\begin{array}{l}\text { Half systemic or } \\
\text { less }\end{array}$ & 78 & $4.8(2.5-9.5)$ & \\
\hline $\begin{array}{l}\text { Initial duration of intubation post- } \\
\text { surgery, days }\end{array}$ & & 90 & $r=0.02$ & 0.84 \\
\hline \multirow[t]{2}{*}{ Re-intubation post-surgery } & Yes & $9 / 90$ & $12.8(6.4-16.9)$ & 0.10 \\
\hline & No & $81 / 90$ & $5.0(2.6-12.3)$ & \\
\hline \multicolumn{2}{|c|}{ Total duration of intubation post-surgery, days } & 90 & $r=0.06$ & 0.56 \\
\hline \multicolumn{2}{|c|}{$\begin{array}{l}\text { Total duration of intubation during hospitalization, } \\
\text { days }\end{array}$} & 92 & $r=0.02$ & 0.85 \\
\hline \multirow[t]{2}{*}{ Seizure post-surgery } & Yes & 6 & $7.6(2.5-12.8)$ & 0.96 \\
\hline & No & 86 & $5.5(2.6-13.4)$ & \\
\hline \multirow[t]{4}{*}{ Brain imaging post-surgery } & Yes & 27 & $6.1(3.1-13.1)$ & 0.47 \\
\hline & Normal findings & $16 / 27$ & $7.1(2.9-14.7)$ & 0.85 \\
\hline & $\begin{array}{l}\text { Abnormal } \\
\text { findings }\end{array}$ & $11 / 27$ & $5.4(3.1-12.8)$ & \\
\hline & No & 65 & $5.3(2.5-13.4)$ & \\
\hline $\begin{array}{l}\text { Total ICU length of stay post- } \\
\text { surgery, days }\end{array}$ & & 92 & $r=0.21$ & 0.046 \\
\hline
\end{tabular}




\begin{tabular}{|c|c|c|c|c|}
\hline \multicolumn{2}{|l|}{ Patient outcomes } & \multirow{2}{*}{$\begin{array}{l}\mathbf{N} \\
5\end{array}$} & \multirow{2}{*}{$\begin{array}{l}\text { Time from birth to } \\
\text { septostomy, hours }\end{array}$} & \multirow{2}{*}{$\begin{array}{l}\begin{array}{l}\text { P- } \\
\text { value }\end{array} \\
0.11\end{array}$} \\
\hline ICU readmission & Yes & & & \\
\hline & No & 91 & $5.3(2.5-13.1)$ & \\
\hline \multicolumn{2}{|c|}{ Hospital length of stay post-surgery, days } & 92 & $r=0.22$ & 0.03 \\
\hline \multicolumn{2}{|c|}{ Hospital length of stay post-septostomy, days } & 96 & $r=0.24$ & 0.02 \\
\hline \multirow[t]{2}{*}{ In-hospital death } & Yes & 3 & $4.9(3.1-12.8)$ & 0.96 \\
\hline & No & 93 & $5.6(2.6-13.4)$ & \\
\hline \multirow[t]{2}{*}{ Deceased } & Yes & 6 & $5.5(3.3-10.2)$ & 0.99 \\
\hline & No & 90 & $5.5(2.5-13.6)$ & \\
\hline \multicolumn{5}{|c|}{$\begin{array}{l}\text { * Data are presented as Median with interquartile range or } r \text {, Spearman correlation coefficient, as } \\
\text { appropriate. }\end{array}$} \\
\hline \multicolumn{5}{|c|}{$\begin{array}{l}\text { § P-value from Wilcoxon rank sum test for categorical variables and Spearman correlation coefficient } \\
\text { for continuous variables. }\end{array}$} \\
\hline
\end{tabular}

\section{Discussion}

In this study, we found that newborns with d-TGA who are delivered outside of a tertiary care center with the ability to perform a BAS had a significantly longer time from birth to BAS. In addition to these patients having lower $\mathrm{PaO} 2$ and receiving increased inotropic support prior to $\mathrm{BAS}$, this increased time from birth to BAS was associated with a longer ICU and hospital length of stay as well as an increased likelihood of elevated RV pressure on discharge echocardiogram. This study adds to literature related to birth location and d-TGA outcomes by evaluating the role of timing of BAS in the overall patient outcomes.

Previous studies in the United States evaluating birth location and/or prenatal diagnosis in this population have focused on mortality as the primary outcome measure [5]. However, in the current surgical era, mortality after arterial switch operation is rare. In addition, most of those studies did not evaluate outcomes based on the timing of BAS. Some prior European and Australian studies have shown no difference in outcomes related to time to BAS, but other data suggests that there is an increased rate of adverse events, higher rates of mechanical ventilation and significant hypoxemia in infants transported from referring facilities [6-9]. In our study, the degree of hypoxia was worse in patients transported from outside facilities. And while duration of mechanical ventilation was not found to be impacted by location of birth or time to BAS in our study, the increased frequency of elevated RV pressure on discharge echocardiogram in those infants who had a later BAS could indicate lasting effects of prolonged, severe neonatal hypoxemia on the pulmonary vasculature. 
We did not identify any acute neurologic sequalae related to timing of BAS. Of note, more patients who had abnormal head imaging underwent earlier BAS. It is possible that those who undergo very rapid BAS (within the first few hours of life), may represent a group of patients with more severe hypoxia or hemodynamic instability. It is not possible to decipher if severity of disease or timing of BAS are independent determinants of abnormal neuroimaging from this study. One limitation to our study is a lack of a standard approach to neuroimaging for the d-TGA patient population. Many patients ( $44 \%$ after BAS and $71 \%$ after surgical repair) had no neuroimaging, and those that did were often limited to a cranial ultrasound which cannot detect subtle changes related to hypoxia. Other studies suggest that newborns with a prenatal diagnosis of critical congenital heart disease (including d-TGA) have less preoperative brain injury on magnetic resonance imaging (MRI) and more robust brain development than those with postnatal diagnosis [10]. Depending on the type of congenital heart disease, postnatally diagnosed infants may have longer duration of hypoxemia, and this may have a similar effect for infants with d-TGA with a longer time from birth to BAS. Therefore, longer term assessment of neurodevelopment and neurocognitive function in these patients, or more global utilization of MRI to assess for brain injury, may help to identify important neurologic outcomes.

The role of prenatal diagnosis using fetal echocardiography is crucial for these patients. While d-TGA has been historically challenging to diagnose prenatally, recent studies cite a detection rate of $50-80 \%$, similar to our study $[11,12]$. Prenatal detection allows for counseling of expectant mothers and often, leads to the birth of these infants at tertiary care centers with the ability to perform urgent interventions such as a BAS. In our study, $72 \%$ of patients were prenatally diagnosed and $99 \%$ of the infants with a prenatal diagnosis delivered at our institution where access to BAS is readily available. Improved fetal detection and delivery planning has been shown to improve overall outcomes for these infants [12]. Some of this improvement in outcomes may be directly related to improved access to and shortened time from birth to BAS.

Approximately $44 \%$ of all patients with d-TGA physiology treated at our center during the study period underwent emergent or urgent BAS. This is consistent with what was seen in a recent multicenter analysis from O'Byrne et al which found an average frequency of BAS of $49 \%$ [13]. Their study noted wide practice variation in the use of BAS amongst various hospitals with some performing them on only $20 \%$ of patients and others on more than $80 \%$ of patients. They also described that BAS was associated with shorter total length of stay and lower hospital cost, which is consistent with our findings that earlier BAS was associated with shorter duration of ICU and hospital length of stay.

In addition to the limitations related to evaluating neurologic sequelae in our study, our sample size and strong correlation between prenatal diagnosis and birth at our institution makes it difficult to distinguish the impact of those variables completely independently. In addition, as a retrospective study, it is not possible to understand or account for subtle differences in patient care management which could have impacted timing of BAS. While a multicenter study may help to find more associations between timing of BAS and patient outcomes, a prospective study would likely be necessary to delineate the impact of birth location and timing of BAS as independent factors. 


\section{Conclusions}

While some infants may continue to be diagnosed with d-TGA postnatally and thus require transport to tertiary care centers, infants prenatally diagnosed with d-TGA benefit from delivery planning that includes birth at a tertiary care center with access to interventional therapies including the ability to perform a rapid BAS. Further research to evaluate neurodevelopmental outcomes in this patient population has the potential to uncover additional effects of prolonged postnatal hypoxia.

\section{Declarations}

Funding: no funding was received to assist with the preparation of this manuscript

Competing interests: not applicable

Availability of data and material: not applicable

Code availability: not applicable

Author's Contributions:

Courtney Thomas: pediatric cardiology fellow, data collection, abstract and manuscript preparation

Sunkyung Yu: statistician, data analysis

Ray Lowery: data manager, creation, and management of database

Jeffrey D. Zampi: faculty mentor, abstract and manuscript preparation and editing

Ethics approval: Institutional review board

Consent to participate: not applicable

Consent for publication: consent for publication of this manuscript is given

\section{References}

1. Villafañe, J., Lantin-Hermoso, M. R., Bhatt, A. B., Tweddell, J. S., Geva, T., Nathan, M., Elliott, M. J., Vetter, V. L., Paridon, S. M., Kochilas, L., Jenkins, K. J., Beekman, R. H., 3rd, Wernovsky, G., Towbin, J. A., \& American College of Cardiology's Adult Congenital and Pediatric Cardiology Council (2014). Dtransposition of the great arteries: the current era of the arterial switch operation. Journal of the American College of Cardiology, 64(5), 498-511. https://doi.org/10.1016/j.jacc.2014.06.1150

2. Donofrio, M. T., Levy, R. J., Schuette, J. J., Skurow-Todd, K., Sten, M. B., Stallings, C., Pike, J. I., Krishnan, A., Ratnayaka, K., Sinha, P., duPlessis, A. J., Downing, D. S., Fries, M. I., \& Berger, J. T. (2013). 
Specialized delivery room planning for fetuses with critical congenital heart disease. The American journal of cardiology, 111(5), 737-747. https://doi.org/10.1016/j.amjcard.2012.11.029

3. Kutty, S., \& Zahn, E. M. (2008). Interventional therapy for neonates with critical congenital heart disease. Catheterization and cardiovascular interventions: official journal of the Society for Cardiac Angiography \& Interventions, 72(5), 663-674. https://doi.org/10.1002/ccd.21705

4. Hanauer DA, Mei Q, Law J, Khanna R, Zheng K. Supporting information retrieval from electronic health records: A report of University of Michigan's nine-year experience in developing and using the Electronic Medical Record Search Engine (EMERSE). J Biomed Inform. 2015 Jun;55:290-300. doi: 10.1016/j.jbi.2015.05.003. Epub 2015 May 13. PMID: 25979153; PMCID: PMC4527540.

5. Lara, D. A., Fixler, D. E., Ethen, M. K., Canfield, M. A., Nembhard, W. N., \& Morris, S. A. (2016). Prenatal diagnosis, hospital characteristics, and mortality in transposition of the great arteries. Birth defects research. Part A, Clinical and molecular teratology, 106(9), 739-748. https://doi.org/10.1002/bdra.23525

6. Veal, C., Hunt, R., \& Tume, L. N. (2019). Do infants with transposition of the great arteries born outside a specialist centre have different outcomes?. Cardiology in the young, 29(8), 1030-1035. https://doi.org/10.1017/S1047951119001367

7. Paul, S., Resnick, S., Gardiner, K. and Ramsay, J.M. (2015), Interstate neonatal cardiac transport. J Paediatr Child Health, 51: 590-594. https://doi.org/10.1111/jpc.12782

8. Woods, P., Browning Carmo, K., Wall, M. and Berry, A. (2013), Transposition of the great arteries. J Paediatr Child Health, 49: E68-E73. https://doi.org/10.1111/jpc.12066

9. Hellström-Westas, L., Hanséus, K., Jögi, P., Lundström, N. R., \& Svenningsen, N. (2001). Long-distance transports of newborn infants with congenital heart disease. Pediatric cardiology, 22(5), 380-384. https://doi.org/10.1007/s002460010254

10. Peyvandi, S., De Santiago, V., Chakkarapani, E., Chau, V., Campbell, A., Poskitt, K. J., Xu, D., Barkovich, A. J., Miller, S., \& McQuillen, P. (2016). Association of Prenatal Diagnosis of Critical Congenital Heart Disease With Postnatal Brain Development and the Risk of Brain Injury. JAMA pediatrics, 170(4), e154450. https://doi.org/10.1001/jamapediatrics.2015.4450

11. Suard, C., Flori, A., Paoli, F., Loundou, A., Fouilloux, V., Sigaudy, S., Michel, F., Antomarchi, J., Moceri, P., Paquis-Flucklinger, V., D'Ercole, C., \& Bretelle, F. (2020). Accuracy of prenatal screening for congenital heart disease in population: A retrospective study in Southern France. PloS one, 15(10), e0239476. https://doi.org/10.1371/journal.pone.0239476

12. Nagata, H., Glick, L., Lougheed, J., Grattan, M., Mondal, T., Thakur, V., Schwartz, S. M., \& Jaeggi, E. (2020). Prenatal Diagnosis of Transposition of the Great Arteries Reduces Postnatal Mortality: A Population-Based Study. The Canadian journal of cardiology, 36(10), 1592-1597. https://doi.org/10.1016/j.cjca.2020.01.010

13. O'Byrne, M. L., Glatz, A. C., Song, L., Griffis, H. M., Millenson, M. E., Gillespie, M. J., Dori, Y., DeWitt, A. G., Mascio, C. E., \& Rome, J. J. (2018). Association Between Variation in Preoperative Care Before 


\section{Figures}

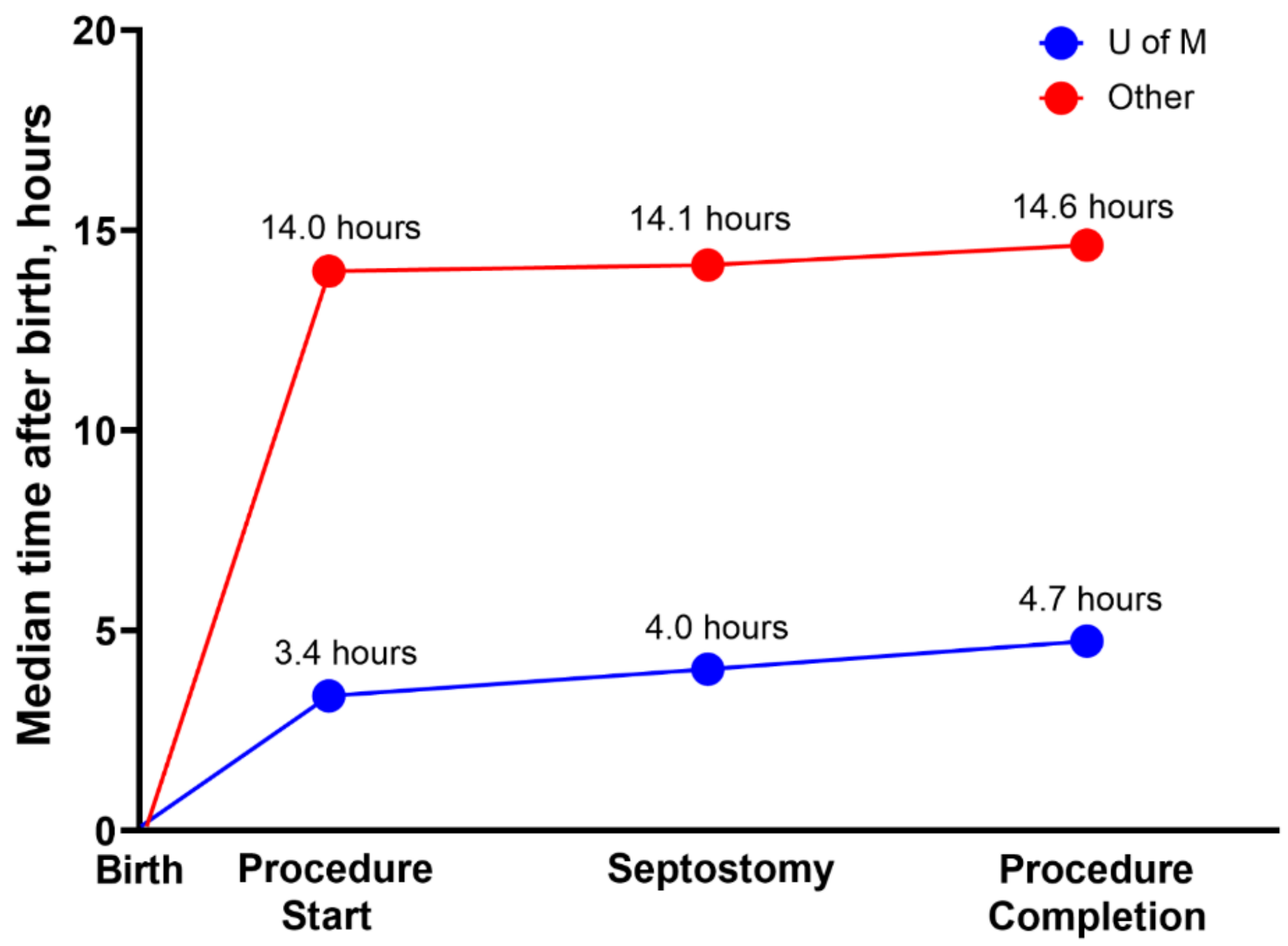

Figure 1

Birth location and time from birth to septostomy 